\title{
Decoy receptor 3 regulates the expression of various genes in rheumatoid arthritis synovial fibroblasts
}

\author{
KOJI FUKUDA ${ }^{1}$, YASUSHI MIURA ${ }^{1,2}$, TOSHIHISA MAEDA ${ }^{1}$, MASAYASU TAKAHASHI ${ }^{3}$, \\ SHINYA HAYASHI $^{1}$ and MASAHIRO KUROSAKA ${ }^{1}$
}

${ }^{1}$ Department of Orthopaedic Surgery, Kobe University Graduate School of Medicine, Chuo, Kobe, Hyogo 650-0017; ${ }^{2}$ Division of Orthopaedic Science, Department of Rehabilitation Science, Kobe University Graduate School of Health Sciences, Suma, Kobe, Hyogo 654-0142; ${ }^{3}$ Department of Orthopaedic Surgery, Kohnan Hospital, Higashinada, Kobe, Hyogo 658-0064, Japan

Received April 11, 2013; Accepted July 18, 2013

DOI: $10.3892 / \mathrm{ijmm} .2013 .1461$

\begin{abstract}
Decoy receptor 3 (DcR3), a member of the tumor necrosis factor (TNF) receptor (TNFR) superfamily, lacks the transmembrane domain of conventional TNFRs in order to be a secreted protein. DcR3 competitively binds and inhibits members of the TNF family, including Fas ligand (FasL), LIGHT and TNF-like ligand 1A (TL1A). We previously reported that TNF $\alpha$-induced DcR3 overexpression in rheumatoid arthritis fibroblast-like synoviocytes (RA-FLS) protects cells from Fas-induced apoptosis. Previous studies have suggested that DcR3 acting as a ligand directly induces the differentiation of macrophages into osteoclasts. Furthermore, we reported that DcR3 induces very late antigen-4 (VLA-4) expression in THP-1 macrophages, inhibiting cycloheximideinduced apoptosis and that DcR3 binds to membrane-bound TL1A expressed on RA-FLS, resulting in the negative regulation of cell proliferation induced by inflammatory cytokines. In the current study, we used cDNA microarray to search for genes in RA-FLS whose expression was regulated by the ligation of DcR3. The experiments revealed the expression profiles of genes in RA-FLS regulated by DcR3. The profiles showed that among the 100 genes most significantly regulated by DcR3, 45 were upregulated and 55 were downregulated. The upregulated genes were associated with protein complex assembly, cell motility, regulation of transcription, cellular protein catabolic processes, cell membrane, nucleotide binding and glycosylation. The downregulated genes were associ-
\end{abstract}

Correspondence to: Dr Yasushi Miura, Division of Orthopaedic Science, Department of Rehabilitation Science, Kobe University Graduate School of Health Sciences, 7-10-2 Tomogaoka, Suma, Kobe, Hyogo 654-0142, Japan

E-mail: miura@kobe-u.ac.jp

Key words: rheumatoid arthritis, fibroblast-like synoviocytes, decoy receptor 3 , microarray assay, gene expression profile ated with transcription regulator activity, RNA biosynthetic processes, cytoskeleton, zinc finger region, protein complex assembly, phosphate metabolic processes, mitochondrion, ion transport, nucleotide binding and cell fractionation. Further study of the genes detected in the current study may provide insight into the pathogenesis and treatment of rheumatoid arthritis by DcR3-TL1A signaling.

\section{Introduction}

Rheumatoid arthritis (RA) is an inflammatory joint disease characterized by hyperplasia of the synovial tissue and formation of pannus, which grows invasively into the cartilage, causing cartilage and bone destruction. Analyses of hyperplastic synovial tissue of patients with RA have revealed a number of features of transformed long-living cells, such as the presence of somatic mutations, expression of oncogenes and resistance to apoptosis (1-3).

We previously reported that the decoy receptor 3 (DcR3)/ TR6/M68/tumor necrosis factor receptor (TNFR) superfamily member 6 (TNFRSF6b) is expressed in rheumatoid fibroblastlike synoviocytes (RA-FLS), and that DcR3 expression induced in RA-FLS by TNF $\alpha$ protects cells from Fas-induced apoptosis (4). DcR3, a member of the TNFR superfamily, lacks the transmembrane domain of conventional TNFRs and thus can be a secreted protein (5). DcR3 is typically overexpressed in tumor cells, including lung and colon cancers (5), gliomas, gastrointestinal tract tumors (6) and virus-associated leukemia (7). In addition, as previous studies have demonstrated, DcR3 is expressed in some normal tissues, including the colon, stomach, spleen, lymph nodes, spinal cord, pancreas and lungs $(5,6)$. However, DcR3 is not expressed in NIH3T3 human fibroblast cells (8). DcR3 has 3 ligands, Fas ligand (FasL), LIGHT and TNF-like ligand 1A (TL1A), which are members of the TNF superfamily (9). The overexpression of DcR3 may benefit tumors by helping them avoid the cytotoxic and regulatory effects of FasL $(5,10)$, LIGHT (11) and TL1A (12). In a previous study, we suggested that DcR3 is one of the key molecules that regulate the proliferation of RA-FLS (4). 
Previous studies have suggested that DcR3 directly induces osteoclast formation from monocytes (13), and that DcR3 triggers the enhanced adhesion of monocytes via reverse signaling (14). We have also reported that DcR3 induces very late antigen-4 (VLA-4) expression in THP-1 macrophages, inhibiting cycloheximide-induced apoptosis (15). As for RA-FLS, in a recent study, we reported that DcR3 binds to membrane-bound TL1A expressed on RA-FLS, resulting in the negative regulation of cell proliferation induced by inflammatory cytokines (16). Therefore, we hypothesized that DcR3 plays a role in the pathogenesis of RA, not only as a decoy receptor, but also as a ligand via TL1A on RA-FLS. However, the function of DcR3 as a ligand in RA-FLS is not yet well understood. In the current study, we searched for genes in RA-FLS whose expression was regulated by the ligation of DcR3 using cDNA microarray. The gene expression profiles may reveal the possible target molecules that play a significant role in the DcR3-TL1A signaling pathway in the pathogenesis of RA.

\section{Materials and methods}

Isolation and culture of synovial fibroblasts. RA-FLS were obtained during total knee replacement surgery from 4 patients (samples 1-4) with RA who fulfilled the 1987 criteria of the American College of Rheumatology (formerly, the American Rheumatism Association) (17), who had never been treated with biological drugs. Synovial samples were collected from the patients who provided written consent in order to participate in this study in accordance with the World Medical Association Declaration of Helsinki Ethical Principles for Medical Research Involving Human Subjects. The protocol, including consent procedures, was approved by Kobe University Graduate School of Medicine Ethics Committee. Tissue specimens were minced and digested in Dulbecco's modified Eagle's medium (DMEM; Gibco BRL, Grand Island, NY, USA) containing $0.2 \%$ collagenase (Sigma, St. Louis, MO, USA) for $2 \mathrm{~h}$ at $37^{\circ} \mathrm{C}$ with $5 \% \mathrm{CO}_{2}$. The dissociated cells were cultured in DMEM supplemented with $10 \%$ fetal bovine serum (FBS; BioWhittaker, Walkersville, MD, USA) and $100 \mathrm{U} / \mathrm{ml}$ of penicillin/streptomycin. Following overnight culture, the non-adherent cells were removed, and the adherent cells were subsequently incubated further in fresh medium. All experiments were conducted using cells from passages 3 to 4 (4).

RNA extraction. Four individual lines (samples 1-4) of primary cultured RA-FLS $\left(2 \times 10^{6}\right.$ cells/well) were incubated with $1.0 \mu \mathrm{g} / \mathrm{ml}$ of recombinant DcR3-Fc protein or control human IgG1 (R\&D Systems, Minneapolis, MN, USA) for $12 \mathrm{~h}$ at $37^{\circ} \mathrm{C}$ with $5 \% \mathrm{CO}_{2}$. Following incubation, RNA was extracted using a QIAshredder and the RNeasy Mini kit (Qiagen, Hilden, Germany) according to the manufacturer's instructions. Extraction of total RNA was performed for each sample separately.

Gene expression profiling and data analysis. Gene expression was detected by microarray (Human Genome U133 Plus 2.0, GeneChip $^{\circledR} 3^{\prime}$ Expression Array; Affymetrix, Santa Clara, CA, USA). The labeling of RNA probes, hybridization and washing were carried out according to the manufacturer's instructions.
Avadis 3.3 Prophetic software (Strand Life Sciences, Bangalore, India) was used for statistical analysis. Differentially expressed genes were extracted by a paired t-test, with a P-value $<0.05$ considered to indicate a statistically significant difference, and fold change $>1.4$, and ordered into hierarchical clusters using the Euclidean algorithm as the distance measure, and the complete algorithm as the linkage method.

Microarray data have been deposited in NCBIs Gene Expression Omnibus (GEO) and are accessible through GEO series accession no. GSE45665.

\section{Results}

Microarray analysis (gene expression profiling of RA-FLS stimulated by $D c R 3-F c$ ). Microarray data analysis revealed that DcR3 upregulated or downregulated the expression of various genes in RA-FLS. We identified the 100 most differentially regulated genes in the DcR3-stimulated group compared with the control IgG1-stimulated group. Among these, 45 genes were upregulated (Table I) and 55 genes were downregulated (Table II).

Hierarchical clustering analysis. The upregulated and downregulated genes were classified into 7 and 10 categories according to their biological functions, respectively (Fig. 1). The upregulated genes were associated with protein complex assembly, cell motility, regulation of transcription, cellular protein catabolic processes, cell membrane, nucleotide binding and glycosylation. The upregulated genes belonging to each cluster are listed in Table III. The downregulated genes were associated with transcription regulator activity, RNA biosynthetic processes, cytoskeleton, zinc finger region, protein complex assembly, phosphate metabolic processes, mitochondrion, ion transport, nucleotide binding and cell fractionation. The downregulated genes belonging to each cluster are listed in Table IV.

\section{Discussion}

Among the 3 ligands of DcR3, TL1A (TNFSF15) is expressed by endothelial cells $(12)$, macrophages $(18,19)$, T cells $(20,21)$, monocytes $(22,23)$, dendritic cells $(23)$, chondrocytes (24) and synovial fibroblasts (24), and contributes to the pathogenesis of cancer and autoimmune diseases via the apoptotic, stress, mitogenic and inflammation pathway by binding death receptor 3 (DR3) and DcR3 (12,25). The 3 ligands of DcR3 have been reported to contribute to the pathogenesis of RA $(4,24,26,27)$. In these studies, DcR3 was considered a decoy receptor for ligands. We previously demonstrated that DcR3 binds to membrane-bound TL1A expressed on RA-FLS when it acts as a ligand in the pathogenesis of RA (16).

Genome-wide gene expression cDNA microarray is a powerful technique used to investigate the pathophysiology of a variety of diseases, including tumors (28-30), immune-mediated diseases $(31,32)$ and inflammatory diseases (33-35). Using microarray, Chang et al revealed that genes characteristically expressed by tumor-associated macrophages were upregulated by DcR3 (30). In the current study, we first demonstrated the expression profiles of genes in RA-FLS regulated by DcR3.

We demonstrated that DcR3 regulates the expression of genes that are mainly associated with the upregulation of the 
Table I. The 45 genes upregulated by DcR3.

\begin{tabular}{|c|c|c|c|c|}
\hline Gene symbol & $\begin{array}{l}\text { Representative } \\
\text { public ID }\end{array}$ & P-value & Fold change & Gene title \\
\hline--- & AW612461 & 0.002695443 & 2.0972981 & --- \\
\hline $\mathrm{CDH} 2$ & NM_001792 & 0.0327261 & 1.9276143 & Cadherin 2 , type $1, \mathrm{~N}$-cadherin (neuronal) \\
\hline AGPAT9 & ВC006236 & 0.006782195 & 1.9184313 & 1-Acylglycerol-3-phosphate O-acyltransferase 9 \\
\hline LOC440944 & ВC036698 & 0.039432783 & 1.8932389 & Hypothetical protein LOC440944 \\
\hline BIVM & ВC039587 & 0.012760683 & 1.6798534 & $\begin{array}{l}\text { Basic, immunoglobulin-like variable motif-containing } \\
\text { protein }\end{array}$ \\
\hline $\mathrm{ZC} 3 \mathrm{H} 3$ & D63484 & 0.02914655 & 1.6767992 & Zinc finger CCCH-type containing 3 \\
\hline IL12B & NM_002187 & 0.008306135 & 1.6463093 & $\begin{array}{l}\text { Interleukin } 12 \mathrm{~B} \text { (natural killer cell stimulatory factor } 2 \text {, } \\
\text { cytotoxic lymphocyte maturation factor } 2, \mathrm{p} 40 \text { ) }\end{array}$ \\
\hline NUB1 & AK026433 & 0.045851827 & 1.6456505 & Negative regulator of ubiquitin-like proteins 1 \\
\hline LTV1 & AW236214 & 0.002476914 & 1.6453595 & LTV1 homolog $($ S. cerevisiae $)$ \\
\hline DMRT2 & AF284225 & 0.033502746 & 1.6123677 & Doublesex and mab-3 related transcription factor 2 \\
\hline SUZ12P & AI820796 & 0.021593563 & 1.5686668 & Suppressor of zeste 12 homolog pseudogene \\
\hline ZBTB1 & BU950380 & 0.039786864 & 1.5227357 & Zinc finger and BTB domain containing 1 \\
\hline--- & N29716 & 0.00277571 & 1.5223095 & --- \\
\hline--- & AK090762 & 0.034467466 & 1.5185958 & --- \\
\hline--- & BG398977 & 0.015083793 & 1.5135463 & --- \\
\hline RANBP17 & NM_022897 & 0.021518266 & 1.5035642 & RAN binding protein 17 \\
\hline GAS5 & BF336936 & 0.041366957 & 1.499078 & Growth arrest-specific 5 (non-protein coding) \\
\hline--- & ВС031996 & 0.011258653 & 1.4903411 & --- \\
\hline REPS 2 & AI984607 & 0.012121066 & 1.4882914 & RALBP1 associated Eps domain containing 2 \\
\hline LOC645158 & ВC018088 & 0.013921799 & 1.4854323 & Hypothetical protein LOC645158 \\
\hline--- & AI332454 & 0.012677074 & 1.4752275 & --- \\
\hline CCDC138 & AU152965 & 0.022518823 & 1.4711432 & Coiled-coil domain containing 138 \\
\hline hCG_1749898 & ВC012486 & 0.002276273 & 1.471024 & KRTAP2-4 protein \\
\hline--- & AI693281 & 0.0196566 & 1.4607961 & --- \\
\hline TUBB2B & AL533838 & 0.006628409 & 1.4584572 & Tubulin, beta $2 \mathrm{~B}$ \\
\hline SLC9A9 & AA029791 & 0.004298657 & 1.4567653 & $\begin{array}{l}\text { Solute carrier family } 9 \text { (sodium/hydrogen exchanger), } \\
\text { member } 9\end{array}$ \\
\hline --- & AA505135 & 0.023416178 & 1.4560933 & --- \\
\hline SLC16A6 & AI873273 & 0.032126337 & 1.4534916 & $\begin{array}{l}\text { Solute carrier family } 16 \text {, member } 6 \text { (monocarboxylic } \\
\text { acid transporter } 7 \text { ) }\end{array}$ \\
\hline --- & AL080112 & 0.035647828 & 1.4486992 & --- \\
\hline LOC100128988 & AI761436 & 0.035967685 & 1.4464797 & Similar to hCG2018847 \\
\hline ZNF252 & AU145662 & 0.015798416 & 1.4447424 & Zinc finger protein 252 \\
\hline FGFR1OP2 & R91766 & 0.021976791 & 1.4398756 & FGFR1 oncogene partner 2 \\
\hline--- & R26931 & 0.03931969 & 1.4398652 & --- \\
\hline ZBTB10 & BG483802 & 0.006168698 & 1.4324573 & Zinc finger and BTB domain containing 10 \\
\hline C3AR1 & U62027 & 0.031616967 & 1.4275972 & Complement component 3 a receptor 1 \\
\hline ZER1 & NM_006336 & 0.000529948 & 1.4270489 & Zer-1 homolog (C.elegans) \\
\hline THRB & BF431989 & 0.027043225 & 1.4229552 & $\begin{array}{l}\text { Thyroid hormone receptor, beta (erythroblastic } \\
\text { leukemia viral (v-erb-a) oncogene homolog } 2 \text {, avian) }\end{array}$ \\
\hline FLJ35220 & AI311040 & 0.008202907 & 1.422941 & Hypothetical protein FLJ35220 \\
\hline CDH10 & NM_006727 & 0.018871933 & 1.4211183 & Cadherin 10, type 2 (T2-cadherin) \\
\hline PEX13 & ВC040953 & 0.00670011 & 1.4182297 & Peroxisomal biogenesis factor 13 \\
\hline C7orf58 & NM_024913 & 0.04462639 & 1.4087468 & Chromosome 7 open reading frame 58 \\
\hline DOK3 & ВC004564 & 0.039809346 & 1.4068991 & Docking protein 3 \\
\hline--- & CA776505 & 0.038875684 & 1.4046313 & --- \\
\hline EGR3 & NM_004430 & 0.008657368 & 1.4038599 & Early growth response 3 \\
\hline ZNF681 & BG281940 & 0.009279283 & 1.4019198 & Zinc finger protein 681 \\
\hline
\end{tabular}

DcR3, decoy receptor 3 . 
Table II. The 55 genes downregulated by DcR3.

\begin{tabular}{|c|c|c|c|c|}
\hline Gene symbol & $\begin{array}{l}\text { Representative } \\
\text { public ID }\end{array}$ & P-value & Fold change & Gene title \\
\hline TPH1 & NM_004179 & 0.022398373 & 2.4520018 & Tryptophan hydroxylase 1 \\
\hline TREML4 & AK090633 & 0.028559439 & 1.9765018 & Triggering receptor expressed on myeloid cells-like 4 \\
\hline CEP70 & AI285884 & 0.038745213 & 1.8690827 & Centrosomal protein $70 \mathrm{kDa}$ \\
\hline $\mathrm{CCNB} 2$ & AK023404 & 0.040380865 & 1.8138049 & Cyclin B2 \\
\hline CCDC121 & NM_024584 & 0.023371078 & 1.8025432 & Coiled-coil domain containing 121 \\
\hline ZNF563 & NM_145276 & 0.01811626 & 1.7816929 & Zinc finger protein 563 \\
\hline PANK2 & AV703394 & 0.025317192 & 1.769196 & Pantothenate kinase 2 \\
\hline--- & N46436 & 0.047841128 & 1.7669531 & --- \\
\hline ZFP28 & AW590434 & 0.011407225 & 1.7393188 & Zinc finger protein 28 homolog (mouse) \\
\hline LOC284926 & BG828817 & 0.04181046 & 1.7324702 & Hypothetical protein LOC284926 \\
\hline SLC24A1 & AF026132 & 0.001774447 & 1.7150456 & $\begin{array}{l}\text { Solute carrier family } 24 \\
\text { (sodium/potassium/calcium exchanger), member } 1\end{array}$ \\
\hline--- & AU146924 & 0.04154287 & 1.699999 & --- \\
\hline SOS2 & L20686 & 0.019266233 & 1.6804754 & Son of sevenless homolog 2 (Drosophila) \\
\hline UBE3B & AL096740 & 0.048379965 & 1.6700492 & Ubiquitin protein ligase E3B \\
\hline ELL & AL521391 & 0.03850427 & 1.6655054 & Elongation factor RNA polymerase II \\
\hline SEZ6L2 & AF131749 & 0.008593195 & 1.6527929 & Seizure related 6 homolog (mouse)-like 2 \\
\hline MB & NM_005368 & 0.024074124 & 1.650637 & Myoglobin \\
\hline--- & ВC040628 & 0.049794715 & 1.6501505 & --- \\
\hline MCOLN3 & NM_018298 & 0.030422723 & 1.6494503 & Mucolipin 3 \\
\hline--- & AK021551 & 0.04994646 & 1.6114371 & --- \\
\hline--- & BF062156 & 0.03806778 & 1.5880637 & --- \\
\hline FBXL17 & AW002273 & 0.003356424 & 1.5799221 & F-box and leucine-rich repeat protein 17 \\
\hline ZNF117 & BF107006 & 0.048431396 & 1.5662925 & Zinc finger protein 117 \\
\hline C1orf230 & AV746331 & 0.007892164 & 1.5605123 & Chromosome 1 open reading frame 230 \\
\hline--- & AA650017 & 0.049496956 & 1.5536357 & --- \\
\hline VKORC1L1 & NM_173517 & 0.01724287 & 1.5391829 & Vitamin K epoxide reductase complex, subunit 1-like 1 \\
\hline MIR155HG & BG231961 & 0.026413728 & 1.5365719 & MIR155 host gene (non-protein coding) \\
\hline KCNAB1 & L39833 & 0.024623908 & 1.534346 & $\begin{array}{l}\text { Potassium voltage-gated channel, shaker-related subfamily, } \\
\text { beta member } 1\end{array}$ \\
\hline--- & AI870634 & 0.048582062 & 1.5243825 & --- \\
\hline YTHDC2 & AW975818 & 0.008661097 & 1.5151424 & YTH domain containing 2 \\
\hline $\mathrm{CCNO}$ & ВC004877 & 0.012114909 & 1.5041811 & Cyclin O \\
\hline C5orf24 & AW068615 & 0.029783456 & 1.5023562 & Chromosome 5 open reading frame 24 \\
\hline--- & AV648424 & 0.032394256 & 1.5009412 & --- \\
\hline ADRBK2 & NM_005160 & 0.034059193 & 1.4894675 & Adrenergic, beta, receptor kinase 2 \\
\hline PIH1D2 & AI744716 & 0.0245486 & 1.477943 & PIH1 domain containing 2 \\
\hline--- & BF224218 & 0.036218014 & 1.4755102 & --- \\
\hline--- & BF591554 & 0.042058036 & 1.474276 & --- \\
\hline GRIN2A & N48896 & 0.006276551 & 1.4638788 & Glutamate receptor, ionotropic, N-methyl D-aspartate $2 \mathrm{~A}$ \\
\hline RABL2A///RABL2B & NM_007082 & 0.00963415 & 1.4549305 & $\begin{array}{l}\text { RAB, member of RAS oncogene family-like } 2 \mathrm{~A} / / / \mathrm{RAB} \text {, } \\
\text { member of RAS oncogene family-like } 2 \mathrm{~B}\end{array}$ \\
\hline MYH14 & ВС000676 & 0.009328251 & 1.4530606 & Myosin, heavy chain 14 \\
\hline LOC727820 & AW340595 & 0.018635018 & 1.4494766 & Hypothetical protein LOC727820 \\
\hline--- & AW074143 & 0.04609772 & 1.448378 & --- \\
\hline ATP5G2 & X69909 & 0.005548685 & 1.4429137 & $\begin{array}{l}\text { ATP synthase, } \mathrm{H}^{+} \text {transporting, mitochondrial F0 complex, } \\
\text { subunit } \mathrm{C} 2 \text { (subunit 9) }\end{array}$ \\
\hline MDM4 & AW269813 & 0.031021323 & 1.4353052 & Mdm4 p53 binding protein homolog (mouse) \\
\hline C11orf84 & AI866590 & 0.02536254 & 1.433334 & Chromosome 11 open reading frame 84 \\
\hline STYX & AW968935 & 0.000515506 & 1.4238193 & Serine/threonine/tyrosine interacting protein \\
\hline
\end{tabular}


Table II. Continued.

\begin{tabular}{|c|c|c|c|c|}
\hline Gene symbol & $\begin{array}{l}\text { Representative } \\
\text { public ID }\end{array}$ & P-value & Fold change & Gene title \\
\hline S100A14 & NM_020672 & 0.03042584 & 1.4226245 & S100 calcium binding protein $\mathrm{A} 14$ \\
\hline--- & BE549780 & 0.020434508 & 1.4224106 & --- \\
\hline NEURL4 & AL136870 & 0.03654641 & 1.4173305 & Neuralized homolog 4 (Drosophila) \\
\hline--- & AI803010 & 0.009107939 & 1.4132907 & --- \\
\hline ETV7 & AF218365 & 0.007053576 & 1.4130081 & Ets variant 7 \\
\hline RBBP9 & AL121893 & 0.01381168 & 1.4109538 & Retinoblastoma binding protein 9 \\
\hline--- & AI298755 & 0.048068948 & 1.4096705 & --- \\
\hline LOC100130855 & AK093077 & 0.008585751 & 1.4052048 & Hypothetical protein LOC100130855 \\
\hline TSFM & AI796813 & 0.005840706 & 1.4036938 & Ts translation elongation factor, mitochondrial \\
\hline
\end{tabular}

DcR3, decoy receptor 3 .

Table III. Functional categories of the 45 upregulated genes classified into 7 categories.

\begin{tabular}{ll}
\hline Functional category & \multicolumn{1}{c}{ Genes } \\
\hline Protein complex assembly & CDH2, RANBP17, REPS2, TUBB2B, PEX13 \\
Cell motility & CDH2, IL12B, PEX13 \\
Regulation of transcription & CDH2, ZC3H3, NUB1, DMRT2, ZBTB1, REPS2, \\
Cellular protein catabolic processes & SLC9A9, ZBTB10, THRB, CDH10, EGR3, ZNF681 \\
Cell membrane & ZER1 \\
& CDH2, AGPAT9, RANBP17, SLC9A9, SLC16A6, C3AR1, \\
Nucleotide binding & CDH10, PEX13, DOK3 \\
Glycosylation & RANBP17, TUBB2B, \\
& CDH2, IL12B, SLC9A9, C3AR1, CDH10, C7orf58
\end{tabular}

Table IV. Functional categories of the 55 downregulated genes classified into 10 categories.

\begin{tabular}{ll}
\hline Functional category & \multicolumn{1}{c}{ Genes } \\
\hline $\begin{array}{l}\text { Transcription regulator activity } \\
\text { RNA biosynthetic processes }\end{array}$ & ZNF563, ZFP28, ELL, ZNF117, CCNO, MDM4, ETV7, TSFM \\
Cytoskeleton & ELL, ZNF117, ETV7, TSFM \\
Zinc finger region & Cep70, CCNB2, GRIN2A, MYH14 \\
& TPH1, ZNF563, ZFP28, SLC24A1, SOS2, ELL, MB, ZNF117, \\
Protein complex assembly & KCNAB1, GRIN2A, MDM4, S100A14, ETV7, RBBP9, TSFM \\
Phosphate metabolic processes & MDM4 \\
Mitochondrion & ADRBK2, ATP5G2, STYX \\
Ion transport & PANK2, ATP5G2, TSFM \\
& TREML4, SLC24A1, SEZ6L2, MB, MCOLN3, VKORC1L1, \\
Nucleotide binding & KCNAB1, GRIN2A, ATP5G2 \\
Cell fractionation & PANK2, YTHDC2, ADRBK2, RABL2A///RABL2B, MYH14 \\
\end{tabular}

protein complex assembly, cell motility and the regulation of transcription, and the downregulation of transcription regulator activity, RNA biosynthetic processes and cytoskeleton. We then focused on the following genes: cadherin 2, type 1 ,
$\mathrm{N}$-cadherin (neuronal) (CDH2), interleukin 12B (natural killer cell stimulatory factor 2 , cytotoxic lymphocyte maturation factor 2, p40) (IL12B), tryptophan hydroxylase 1 (TPH1), centrosomal protein $70 \mathrm{kDa}(\mathrm{Cep} 70)$ and Zinc finger proteins 


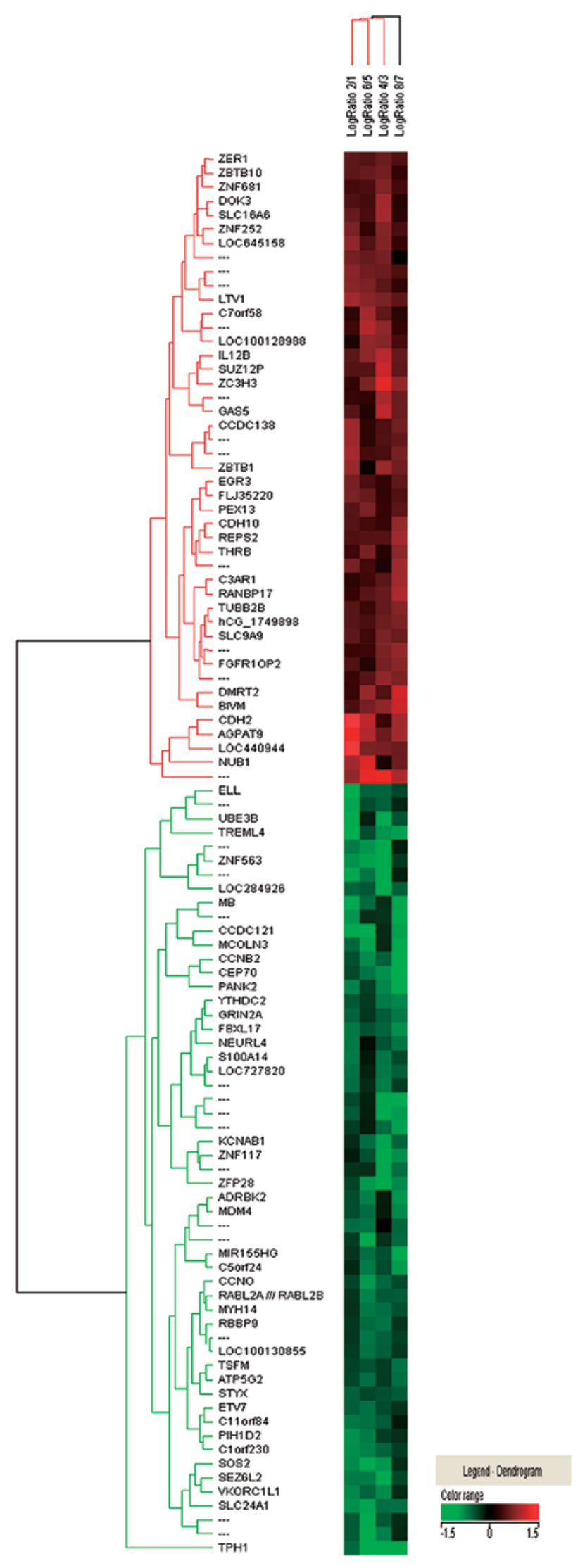

Figure 1. Cluster analysis and heat map of 100 significantly regulated probe sets. The heat map illustrates the expression values mapped to a color gradient from low (green) to high expression (red). Experiments are arranged according to a hierarchical clustering dendrogram. The horizontal dendrogram illustrates the similarity of functions between neighboring genes. The vertical dendrogram shows similarities in gene expression between neighboring samples. as these genes were highly regulated, either upregulated or downregulated, and belonged to major functional clustering categories.

As for each gene, $\mathrm{CDH} 2$ has been reported to be associated with cell attachment and migration (36), metastatic potential (37), osteoblast differentiation (38) and the proliferation of RA-FLS (39).

IL12B encodes the IL-12B p40 subunit of IL-12 and IL-23 cytokines. IL-12 induces Th1 immune responses, and is thus linked with autoimmune diseases (40), while IL-23 is linked with autoimmune diseases via Th17 immune responses (41). IL-12 $(42)$ and IL-23 $(43,44)$ have also been reported to be involved in the pathogenesis of RA.

TPH1 is a rate-limiting enzyme involved in the synthesis of serotonin, and has been reported to be associated with the pathogenesis of RA through the inflammatory pathway (45) and bone biology (46-48).

Cep70 was discovered in a proteomic study of the centrosome (49). Centrosomal activity is indispensable for the execution of cytokinesis and the progression of the cell cycle (50). Cep70 is crucial for mitotic spindle assembly (51) and promotes microtubule polymerization by increasing microtubule elongation (52).

Zinc finger proteins are involved in a broad range of biological activities, including double-stranded DNA binding, single-stranded DNA and RNA recognition, as well as coordinating protein-protein interactions (53).

In the current study, we first reported the expression profiles of genes in RA-FLS regulated by DcR3. Combined with our previous findings that DcR3 serves as a ligand by binding to membrane-bound TL1A on RA-FLS, our data demonstrate that DcR3 may regulate the gene expression of various key molecules in RA-FLS by binding to TL1A, thus affecting the pathogenesis of RA, such as proliferation, apoptosis, inflammation and bone biology. Further studies on the genes detected in the current study may provide a deeper understanding of the pathogenesis and treatment of RA by DcR3-TL1A signaling.

\section{Acknowledgements}

The authors thank Ms. Kyoko Tanaka, Ms. Minako Nagata, and Ms. Maya Yasuda for providing technical assistance. This study was supported by a Grant-in-Aid from the Health Science Research Grant of the Japanese Ministry of Education, Science and Culture (no. 24592261).

\section{References}

1. Chou CT, Yang JS and Lee MR: Apoptosis in rheumatoid arthritis - expression of Fas, Fas-L, p53, and Bcl-2 in rheumatoid synovial tissues. J Pathol 193: 110-116, 2001.

2. Tak PP, Zvaifler NJ, Green DR and Firestein GS: Rheumatoid arthritis and p53: how oxidative stress might alter the course of inflammatory diseases. Immunol Today 21: 78-82, 2000.

3. Yamanishi Y, Boyle DL, Rosengren S, Green DR, Zvaifler NJ and Firestein GS: Regional analysis of p53 mutations in rheumatoid arthritis synovium. Proc Natl Acad Sci USA 99: 10025-10030, 2002.

4. Hayashi S, Miura Y, Nishiyama T, et al: Decoy receptor 3 expressed in rheumatoid synovial fibroblasts protects the cells against Fas-induced apoptosis. Arthritis Rheum 56: 1067-1075, 2007.

5. Pitti RM, Marsters SA, Lawrence DA, et al: Genomic amplification of a decoy receptor for Fas ligand in lung and colon cancer. Nature 396: 699-703, 1998. 
6. Bai C, Connolly B, Metzker ML, et al: Overexpression of M68/DcR3 in human gastrointestinal tract tumors independent of gene amplification and its location in a four-gene cluster. Proc Natl Acad Sci USA 97: 1230-1235, 2000.

7. Ohshima K, Haraoka S, Sugihara M, et al: Amplification and expression of a decoy receptor for fas ligand (DcR3) in virus (EBV or HTLV-I) associated lymphomas. Cancer Lett 160: 89-97, 2000.

8. Chen J, Zhang L and Kim S: Quantification and detection of DcR3, a decoy receptor in TNFR family. J Immunol Methods 285: 63-70, 2004.

9. Shi G, Wu Y, Zhang J and Wu J: Death decoy receptor TR6/DcR3 inhibits T cell chemotaxis in vitro and in vivo. J Immunol 171: 3407-3414, 2003.

10. Tsuji S, Hosotani R, Yonehara S, et al: Endogenous decoy receptor 3 blocks the growth inhibition signals mediated by $\mathrm{Fas}$ ligand in human pancreatic adenocarcinoma. Int J Cancer 106: $17-25,2003$.

11. Yu KY, Kwon B, Ni J, Zhai Y, Ebner R and Kwon BS: A newly identified member of tumor necrosis factor receptor superfamily (TR6) suppresses LIGHT-mediated apoptosis. J Biol Chem 274: 13733-13736, 1999.

12. Migone TS, Zhang J, Luo X, et al: TL1A is a TNF-like ligand for DR3 and TR6/DcR3 and functions as a T cell costimulator. Immunity 16: 479-492, 2002

13. Yang CR, Wang JH, Hsieh SL, Wang SM, Hsu TL and Lin WW: Decoy receptor 3 (DcR3) induces osteoclast formation from monocyte/macrophage lineage precursor cells. Cell Death Differ 11 (Suppl 1): S97-S107, 2004.

14. Hsu MJ, Lin WW, Tsao WC, et al: Enhanced adhesion of monocytes via reverse signaling triggered by decoy receptor 3 . Exp Cell Res 292: 241-251, 2004.

15. Tateishi K, Miura Y, Hayashi S, Takahashi M and Kurosaka M: DcR3 protects THP-1 macrophages from apoptosis by increasing integrin alpha4. Biochem Biophys Res Commun 389: 593-598, 2009.

16. Takahashi M, Miura Y, Hayashi S, Tateishi K, Fukuda K and Kurosaka M: DcR3-TL1A signalling inhibits cytokine-induced proliferation of rheumatoid synovial fibroblasts. Int J Mol Med 28: 423-427, 2011

17. Arnett FC, Edworthy SM, Bloch DA, et al: The American Rheumatism Association 1987 revised criteria for the classification of rheumatoid arthritis. Arthritis Rheum 31: 315-324, 1988.

18. Kamada N, Hisamatsu T, Honda H, et al: TL1A produced by lamina propria macrophages induces Th1 and Th17 immune responses in cooperation with IL-23 in patients with Crohn's disease. Inflamm Bowel Dis 16: 568-575, 2010.

19. Bamias G, Martin C III, Marini M, et al: Expression, localization, and functional activity of TL1A, a novel Th1-polarizing cytokine in inflammatory bowel disease. J Immunol 171: 4868-4874, 2003.

20. Prehn JL, Mehdizadeh S, Landers CJ, et al: Potential role for TL1A, the new TNF-family member and potent costimulator of IFN-gamma, in mucosal inflammation. Clin Immunol 112: 66-77, 2004.

21. Papadakis KA, Zhu D, Prehn JL, et al: Dominant role for TL1A/ DR3 pathway in IL-12 plus IL-18-induced IFN-gamma production by peripheral blood and mucosal CCR $9^{+} \mathrm{T}$ lymphocytes. J Immunol 174: 4985-4990, 2005.

22. Cassatella MA, Pereira-da-Silva G, Tinazzi I, et al: Soluble TNF-like cytokine (TL1A) production by immune complexes stimulated monocytes in rheumatoid arthritis. J Immunol 178 7325-7333, 2007.

23. Prehn JL, Thomas LS, Landers CJ, Yu QT, Michelsen KS and Targan SR: The T cell costimulator TL1A is induced by FcgammaR signaling in human monocytes and dendritic cells J Immunol 178: 4033-4038, 2007.

24. Zhang J, Wang X, Fahmi H, et al: Role of TL1A in the pathogenesis of rheumatoid arthritis. J Immunol 183: 5350-5357, 2009.

25. Sethi G, Sung B and Aggarwal BB: Therapeutic potential of VEGI/TL1A in autoimmunity and cancer. Adv Exp Med Biol 647: 207-215, 2009.

26. Bamias G, Siakavellas S, Stamatelopoulos K, Chryssochoou E, Papamichael C and Sfikakis P: Circulating levels of TNF-like cytokine 1A (TL1A) and its decoy receptor 3 (DcR3) in rheumatoid arthritis. Clin Immunol 129: 249-255, 2008.

27. Edwards JR, Sun SG, Locklin R, et al: LIGHT (TNFSF14), a novel mediator of bone resorption, is elevated in rheumatoid arthritis. Arthritis Rheum 54: 1451-1462, 2006.

28. Khan J, Simon R, Bittner M, et al: Gene expression profiling of alveolar rhabdomyosarcoma with cDNA microarrays. Cancer Res 58: 5009-5013, 1998.
29. Espinosa I, Catasus L, Canet B, D'Angelo E, Munoz J and Prat J: Gene expression analysis identifies two groups of ovarian highgrade serous carcinomas with different prognosis. Mod Pathol 24: 846-854, 2011

30. Chang YC, Chen TC, Lee CT, et al: Epigenetic control of MHC class II expression in tumor-associated macrophages by decoy receptor 3. Blood 111: 5054-5063, 2008.

31. Li J, Yang S, Lu S, et al: Differential gene expression profile associated with the abnormality of bone marrow mesenchymal stem cells in aplastic anemia. PLoS One 7: e47764, 2012.

32. Whitney LW, Becker KG, Tresser NJ, et al: Analysis of gene expression in mutiple sclerosis lesions using cDNA microarrays. Ann Neurol 46: 425-428, 1999.

33. Heller RA, Schena M, Chai A, et al: Discovery and analysis of inflammatory disease-related genes using cDNA microarrays. Proc Natl Acad Sci USA 94: 2150-2155, 1997.

34. Lee SK, Jeon EK, Kim YJ, et al: A global gene expression analysis of the peripheral blood mononuclear cells reveals the gene expression signature in psoriasis. Ann Dermatol 21: 237-242, 2009.

35. van der Pouw Kraan TC, van Gaalen FA, Kasperkovitz PV, et al: Rheumatoid arthritis is a heterogeneous disease: evidence for differences in the activation of the STAT-1 pathway between rheumatoid tissues. Arthritis Rheum 48: 2132-2145, 2003.

36. Akitaya T and Bronner-Fraser M: Expression of cell adhesion molecules during initiation and cessation of neural crest cell migration. Dev Dyn 194: 12-20, 1992.

37. Kashima T, Nakamura K, Kawaguchi J, et al: Overexpression of cadherins suppresses pulmonary metastasis of osteosarcoma in vivo. Int J Cancer 104: 147-154, 2003

38. Marie PJ: Role of $\mathrm{N}$-cadherin in bone formation. J Cell Physiol 190: 297-305, 2002.

39. Nonomura Y, Mizoguchi F, Suzuki A, et al: Hypoxia-induced abrogation of contact-dependent inhibition of rheumatoid arthritis synovial fibroblast proliferation. J Rheumatol 36: 698-705, 2009.

40. Hasko G and Szabo C: IL-12 as a therapeutic target for pharmacological modulation in immune-mediated and inflammatory diseases: regulation of $\mathrm{T}$ helper $1 / \mathrm{T}$ helper 2 responses. Br J Pharmacol 127: 1295-1304, 1999.

41. Paradowska-Gorycka A, Grzybowska-Kowalczyk A Wojtecka-Lukasik E and Maslinski S: IL-23 in the pathogenesis of rheumatoid arthritis. Scand J Immunol 71: 134-145, 2010.

42. Swaak AJ, van den Brink HG and Aarden LA: Cytokine production in whole blood cell cultures of patients with rheumatoid arthritis. Ann Rheum Dis 56: 693-695, 1997.

43. Liu FL, Chen CH, Chu SJ, et al: Interleukin (IL)-23 p19 expression induced by IL-1beta in human fibroblast-like synoviocytes with rheumatoid arthritis via active nuclear factor-kappaB and AP-1 dependent pathway. Rheumatology (Oxford) 46: 1266-1273, 2007.

44. Kim HR, Cho ML, Kim KW, et al: Up-regulation of IL-23p19 expression in rheumatoid arthritis synovial fibroblasts by IL-17 through PI3-kinase-, NF-kappaB- and p38 MAPK-dependent signalling pathways. Rheumatology (Oxford) 46: 57-64, 2007.

45. Kular L, Pakradouni J, Kitabgi P, Laurent M and Martinerie C: The CCN family: a new class of inflammation modulators? Biochimie 93: 377-388, 2011.

46. Yadav VK and Ducy P: Lrp5 and bone formation. Ann NY Acad Sci 1192: 103-109, 2010.

47. Gustafsson BI, Thommesen L, Stunes AK, et al: Serotonin and fluoxetine modulate bone cell function in vitro. J Cell Biochem 98: 139-151, 2006.

48. Ducy P and Karsenty G: The two faces of serotonin in bone biology. J Cell Biol 191: 7-13, 2010.

49. Andersen JS, Wilkinson CJ, Mayor T, Mortensen P, Nigg EA and Mann M: Proteomic characterization of the human centrosome by protein correlation profiling. Nature 426: 570-574, 2003.

50. Doxsey S, Zimmerman W and Mikule K: Centrosome control of the cell cycle. Trends Cell Biol 15: 303-311, 2005.

51. Shi X, Sun X, Liu M, Li D, Aneja R and Zhou J: CEP70 protein interacts with gamma-tubulin to localize at the centrosome and is critical for mitotic spindle assembly. J Biol Chem 286: 33401-33408, 2011

52. Shi X, Wang J, Yang Y, Ren Y, Zhou J and Li D: Cep70 promotes microtubule assembly in vitro by increasing microtubule elongation. Acta Biochim Biophys Sin (Shanghai) 44: 450-454, 2012.

53. Leon $\mathrm{O}$ and Roth M: Zinc fingers: DNA binding and proteinprotein interactions. Biol Res 33: 21-30, 2000. 